\title{
SIMULATION OF THE MECHANICAL STIMULATION EFFECT ON THE PEN JUNCTION BETWEEN BONE AND PELVIC BASED ON FINITE ELEMENT METHODS
}

\author{
Khusnul Yakin* \\ Department of Physics, Universitas Islam Negeri Maulana Malik Ibrahim Malang \\ Jl. Gajayana No. 50 Malang 65144
}

Received: $9^{\text {th }}$ February 2020; Revised: $19^{\text {th }}$ March 2020; Accepted: $3^{\text {rd }}$ April 2020

\begin{abstract}
Bone remodeling process influenced by cells osteoblast and osteoclast. The remodeling of cortical and trabecular influenced by mechanical stimuli. In this study, cortical and trabecular bones of 25 years old humans were observed, and the result was the cortical bone has the average Young's modulo 17.9 MPa with the Poisson's ratio of 0.4. Trabecular bone has the average Young's modulo of $13 \mathrm{MPa}$ and the Poisson's ratio of 0.5 . The metal orthopedic bone screw, which has used in this research simulation, was is a Titanium screw. The screw has Young's modulo of $110 \mathrm{GPa}$ and the Poisson's ratio of 0.29 . The results of the simulation of femoral bone elasticity limit with standing activity at the age of 25 were found in the left femur of $112.9416 \mathrm{MPa}$ and the right femur of $115.5134 \mathrm{MPa}$. The limit of elasticity of the femur due to walking was found in the left femur of 115.2166 $\mathrm{MPa}$ with an accuracy of $94.11 \%$ and the right femur of $117.6692 \mathrm{MPa}$.
\end{abstract}

Keywords: Bone Remodeling; Mechanical Stimuli; Titanium; Bone Density

\section{Introduction}

The major components of a bone are cortical and trabecular, which are continuously experienced destruction and repairs through the remodeling bone process. ${ }^{1}$ This remodeling process involves reabsorption of the old bone by osteoclasts and the formation of at the new bone by osteoblasts. $^{2}$

Based on the research of Gholamreza Rouhi shows showed that bone density determined by mechanical stimuli. ${ }^{3}$ Bone density may slow down or increased depending on the size of the burden of a mechanic who accepted. ${ }^{3}$ In addition to mechanical, stimuli it also affects the age of bone density. According to Keaveny et al. 2004, the bones in humans will increase solid and getting longer and longer up to density maximum at the age of 30 years. After age 30 years, bone density will decrease even can cause a decrease in height. ${ }^{4}$

\footnotetext{
*Corresponding author.

E-Mail: khusnulyakin@ uin-malang.ac.id
}

One disease caused by a lack of bone density is osteoporosis. Osteoporosis is a condition marked by bone density mineral low and damage structure micro bone tissue. This is what led to an increase in vulnerability bone and to get broken bones. When there were broken bones, it will be done connection of bone with a pen as a method of the cure.

Research on mechanical stimulation of bone remodeling has been done by some researchers but could not explain how this is an implant pen on the boundary elasticity of bones. V. Klika and F. Marsik in 2006 use the model RANK-RANKL-OPG to lower the equation differential bone remodeling. ${ }^{3}$ Then be continued in 2010. They were studying the model thermodynamics remodeling bone that could explain the process of the activity of osteoblast by modifying than ever. ${ }^{3}$ While in 2013, Ahmad Idhammad et al. did research simulation of the femur bone remodeling due 
to mechanical stimuli but, analysis of this study cannot explain the influence of mechanical stimuli on remodeling and limit the elasticity of bones on the bone-implant connection. $^{7}$ In 2014, Khusnul Yakin developed the V. Klika and F. Marsik using an element of the finite method for determining the density of bone and the elasticity but does not extend to the bone with a pen. ${ }^{8}$

A clinical trial was conducted in the patients who have a fracture in which the bone connects with a pen. Because there was a pen that had implant into the bone, it will influence bone remodeling. For it, researchers interested in the implant pen on the remodeling influence on the bone that is by counting bone density and the elasticities around the pen.

This research includes four phases. The first stage is the construction of the femur bone connection pen in Matlab. Were then followed by coming in and simulate this voltage, strain, and strain rate on a bone. In the long term, the calculated density is of bone with the equation of thermodynamics V. Klika and F. Marsik, and the phase most recently is measuring the maximum limit the elasticity of bone. The purpose of the research is to simulate the spread of stress, strain, and strain rate on bony tissue resulting from stimulation mechanics and changes in the age of the femur bone changes density and limit the elasticity of the femur bone around the junction of bones.

\section{Methods}

\section{Construction geometry connection bone}

Construction geometry bone made in the form of the femur bone.Geometry bone consisting of 1580 elements where each element a triangular-shaped with a wide 0.01 $\mathrm{m}$ and high construction $0.002 \mathrm{~m}$. Femur bone made two layers of where the inner layer of the trabecular bone while the outer layer of cortical bone. The observation is made at certain points the head of the femur, the neck the femur, stems the femur left and stems the femur right shown in point number 1 to 8 in figure 1 .

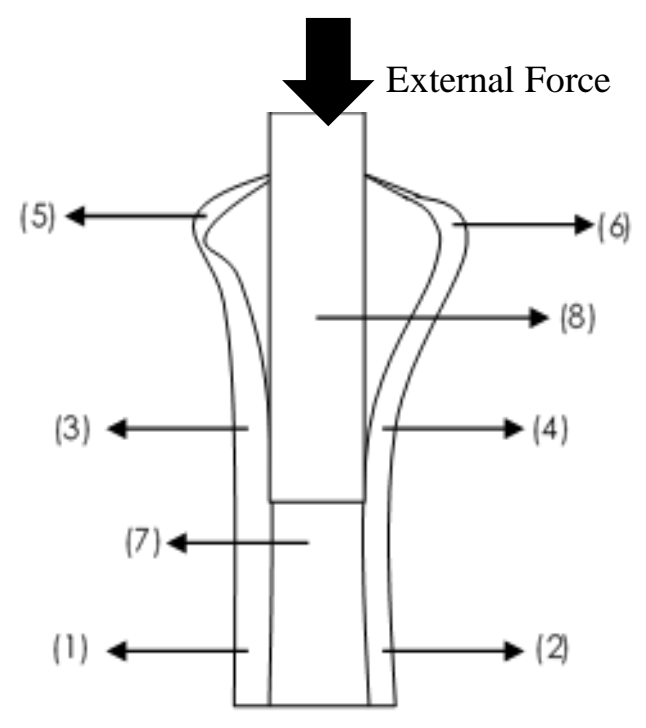

Figure 1. Construction of the femur bone connection

\section{The input of the mechanical properties}

The mechanical properties of bones show the nature of violence and stiffness given by value Young's modulo and the Poisson's ratio. This research gave treatment differences in age bone the age of 25 years old and 45 years. The cortical age of 25 years has Young's modulo of $17.9 \mathrm{MPa}$ and the Poisson's ratio 0.4 , while the trabecular having Young's modulo $13 \mathrm{MPa}$ and the Poisson's ratio 0.5 . The cortical age 45 years have Young's modulo 17.184 MPa and the Poisson's ratio 0.5, while the trabecular having Young's modulo $10.4 \mathrm{MPa}$ to a Poisson's ratio 0.6. In addition, the pen used is metal titanium in which it has Young's modulo $110 \mathrm{GPa}$ and the Poisson's ratio 0.29 .

\section{Mechanical input stimuli}

A force that accepted the femur bone following activities performed by patients. This study considers the activity of the patient is up and running normally. If severe patients considered $65 \mathrm{Kg}$ weight, then the calculation style received by the femur bone on the activity of stand up and running shown in table 1 . The mechanical force exerted on the connection of the femur with the femur in element 964 (figure 1). 


\section{Simulated distribution stress, strain, and strain rate}

A simulation distribution stress, strain, and strain rate are done with a method of finite element. Calculations were done; every element of elements that have mechanical stimuli came to all the femur bone. Calculation stress and the strain was done with equation (1-4), Which previously calculated his first displacement value equation (5-7). The value of stress, strain, and strain rate will be shown at the point 1-8 as a figure 1 .

$$
\{\sigma\}=\left\{\sigma_{\mathrm{x}} \sigma_{\mathrm{y}} \tau_{\mathrm{xy}}\right\}^{\mathrm{T}}
$$

$$
\begin{aligned}
& \{\varepsilon\}=\left\{\varepsilon_{\mathrm{x}} \varepsilon_{\mathrm{y}} \varepsilon_{\mathrm{xy}}\right\}^{\mathrm{T}} \\
& {[D]=\frac{E}{1-v^{2}}\left[\begin{array}{ccc}
1 & v & 0 \\
v & 1 & 0 \\
0 & 0 & \frac{1-v}{2}
\end{array}\right]} \\
& \{\sigma\}=[D]\{\varepsilon\} \\
& \int_{\Omega^{*}}[\mathrm{~B}]^{\mathrm{T}}[\mathrm{D}][\mathrm{B}] \mathrm{d} \Omega\{\mathrm{d}\} \\
& {\left[\mathrm{K}^{\mathrm{e}}\right]=\int_{\Omega^{*}}[\mathrm{~B}]^{\mathrm{T}}[\mathrm{D}][\mathrm{B}] \mathrm{d} \Omega} \\
& {\left[\mathrm{K}^{\mathrm{e}}\right]\left\{\mathrm{d}^{\mathrm{e}}\right\}=\left\{\mathrm{f}^{\mathrm{e}}\right\}}
\end{aligned}
$$

Table 1. The force received the connection a result of the difference physical activity

\begin{tabular}{ccc}
\hline Activity & Calculation & Result \\
\hline Stand & $\frac{1.8+2.2}{2} \times 650$ & $1300 \mathrm{~N}$ \\
Walking Normally & $\frac{1.6+4.1}{2} \times 650$ & $1755 \mathrm{~N}$ \\
\hline
\end{tabular}

\section{Calculation Bone Density of The Femur}

Calculation bone density to stimuli mechanic was done using Runge-Kutta orde4 on equations (8-11) with software 2008 Matlab. Variable of strain rate obtained from the simulated the pressure, strain, and strain rate included equation (10), which in turn affecting the calculation equation (8).

$$
\begin{aligned}
& \frac{\mathrm{dn}_{\mathrm{MCELL}}}{\mathrm{d} \tau}=-\delta_{1}\left(\beta_{1}+\mathrm{n}_{\mathrm{MCELL}}\right) \mathrm{n}_{\mathrm{MCELL}}+\mathrm{J}_{3}+\mathrm{J}_{\mathrm{New}_{-} \mathrm{B}} \\
& -D_{1} \\
& \frac{\mathrm{dn}_{\text {Old_B }}}{\mathrm{d} \tau}=-\left(\beta_{3}-\mathrm{n}_{\text {MCELL }}+\mathrm{n}_{\text {Old_B }}\right) \mathrm{n}_{\text {Old_B }}-D_{2} \\
& +\mathrm{J}_{\mathrm{NeW}_{-} \mathrm{B}} \\
& \frac{\mathrm{dn}_{\mathrm{OB}}}{\mathrm{d} \tau}=\delta_{3}\left(\beta_{6}-\mathrm{n}_{\mathrm{Old}_{\mathrm{B}}}-\left(\mathrm{n}_{\mathrm{OB}}+\mathrm{n}_{\text {Osteoid }}+\mathrm{n}_{\mathrm{New}_{\mathrm{B}}}\right)\right)\left(\beta_{8}\right. \\
& \left.-\left(\mathrm{n}_{\mathrm{OB}}+\mathrm{n}_{\text {Osteoid }}+\mathrm{n}_{\mathrm{New}_{\mathrm{B}}}\right)\right) \\
& -\delta_{4}\left(\beta_{11}-\left(\mathrm{n}_{\text {Osteoid }}+\mathrm{n}_{\text {New_B }}\right) \mathrm{n}_{\mathrm{OB}}\right) \\
& +\mathrm{D}_{3}-\mathrm{D}_{4}
\end{aligned}
$$

$$
\begin{aligned}
& \frac{\mathrm{dn}_{\text {Osteoid }}}{\mathrm{d} \tau}=\delta_{4}\left(\beta_{11}-\left(\mathrm{n}_{\text {Osteoid }}+\mathrm{n}_{\text {New }}\right)\right) \mathrm{n}_{\mathrm{OB}} \\
& -\delta_{5}\left(\beta_{14}-n_{\text {NewB }}\right) n_{\text {Osteoid }}+D_{4}-D_{5} \\
& \frac{\mathrm{dn}_{\mathrm{New} \_} \mathrm{B}}{\mathrm{d} \tau}=\delta_{5}\left(\beta_{14}-\mathrm{n}_{\mathrm{New}_{\_} \mathrm{B}}\right) \mathrm{n}_{\text {Osteoid }}-\mathrm{J}_{\mathrm{New}_{-} \mathrm{B}}+\mathrm{D}_{5} \\
& \delta_{\alpha}=\frac{\mathrm{k}_{+\alpha}}{\mathrm{k}_{+2}} \\
& \mathrm{D}_{\alpha}=\frac{\mathrm{l}_{\alpha \mathrm{v}} \mathrm{d}_{(1)}}{\mathrm{k}_{+2}[\mathrm{Bo}]^{2}} \\
& \rho(\mathrm{I})=\rho_{0}\left(\mathrm{~N}_{\mathrm{Old}_{\mathrm{B}}}(\mathrm{I})+\mathrm{N}_{\mathrm{New}_{\mathrm{B}}}(\mathrm{I})\right) \\
& \mathrm{E}(\mathrm{I})=\mathrm{E}_{0} \mathrm{C}\left(\frac{\rho(\mathrm{I})}{\rho_{0}}\right)^{3} \mathrm{C}=\text { Constant }
\end{aligned}
$$

\section{Calculation The Limits The Elasticity of Bones}

Limits the elasticity of bones calculated by counting stress and strain until on the boundary broken. Broken bone tissue, then the amount be matched with experimental (the available data in the hospital). If the 
results of computing obtained are already fit, then it can be applied to the other bone implant.

\section{Result and Discussion}

\section{Construction of the femur bone junction}

Construction of bones in connection of the femur bone consisting of 1712 an element and 964 points. Each element of a triangle was arranged to form a connection pen on a bone of the femur. Triangular element with a pedestal one centimeter and high two centimeters sides. Figure 2, with a blue color element, was cortical, of a green color which is in cortical was trabecular in bone, while the red is pen connection on a bone of the femur. Construction of the femur bone was built in two dimensions with wide the average of $10 \mathrm{~cm}$ during the high about 35 $\mathrm{cm}$.

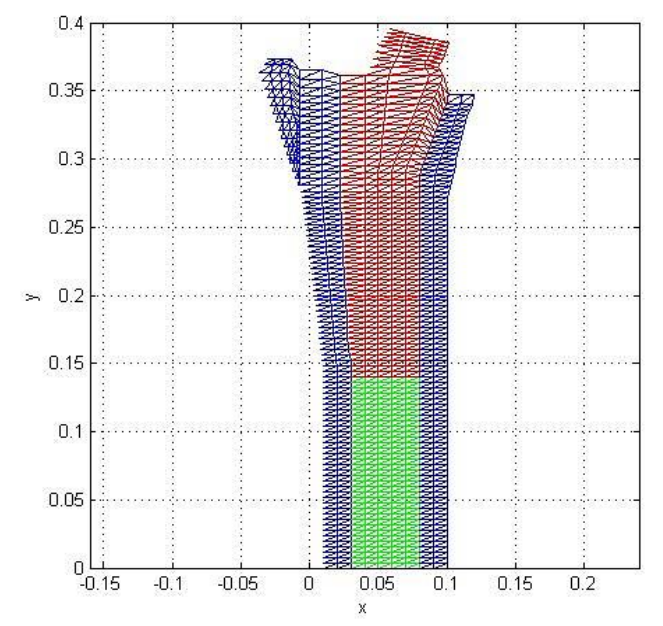

Figure 2. Construction connection the femur bone with finite element methods

The input results of the nature of the bone were conducted by inserting the value of Young's modulo and the ratio of Poisson bone and pen. The value of Young's modulo and the ratio of Poisson included was a bone with age 25 and 45 years. While pen being used is titanium alloy simulated data input mechanical properties of bone shown in figure 3. A blue color reflects Young's modulo of the cortical; a brown color reflects Young's modulo pen. While our value Young's modulo bone trabecular does not look due to having value Young's modulo is small compared to the cortical and pens.

\section{Simulation of Distribution Stress, Strain, and Strain rate}

Distribution stress occurs in the femur occurring in uneven. The largest stress is on the stem of the femur. Figure 4 shows the red and blue is the largest stress contained in a cortical bone femur. The cortical femur bone, the right stress blue (in the negative) showing happened compression on the bones. While the left cortical red (are positive) shows bone cell experienced stretch. This is in accordance with the calculation of Martini in the year 2009. ${ }^{9}$

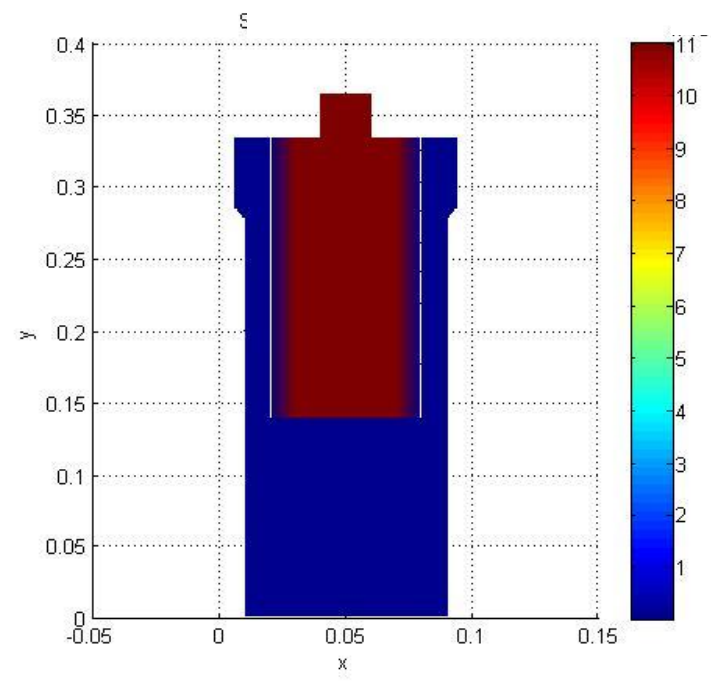

Figure 3. Simulated input mechanical properties bone and pen

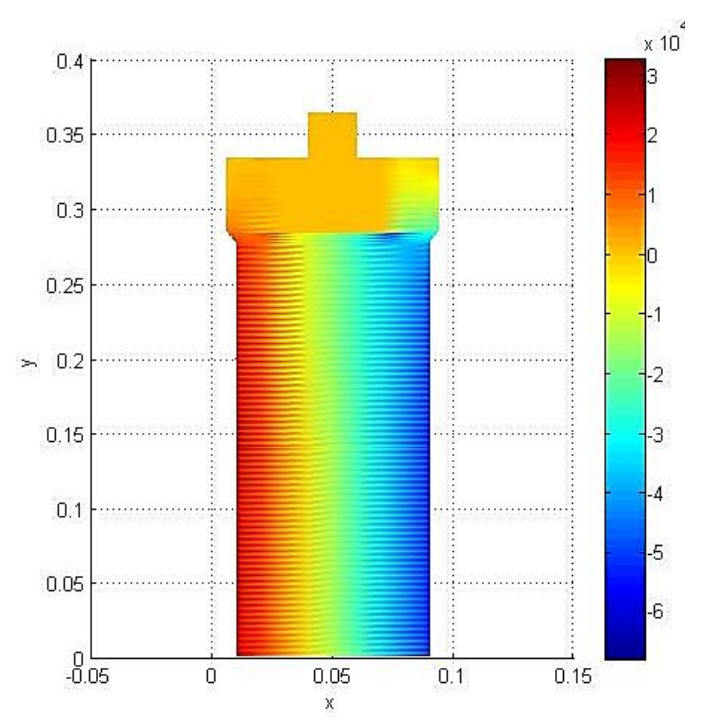

Figure 4. Distribution of stress on the femur 
Trabecular bone has a smaller stress value than cortical bone because the trabecular bone is located on the inside so that the distribution of stress is more on cortical bone. Titanium metal can withstand the stresses originating from mechanical stimulation so that the stress felt at the bone joint with the pen tends to be small Distribution strain in proportion to the distribution of stress. Distribution strain largest is also in the cortical stems the femur. Strain the cortical stems right is higher than stems left. The distribution of the strain rate (figure 5) is proportional to the distribution of strain. The only value is always positive the calculation of stress, strain, and strain rate used in the observation given in table 2 .

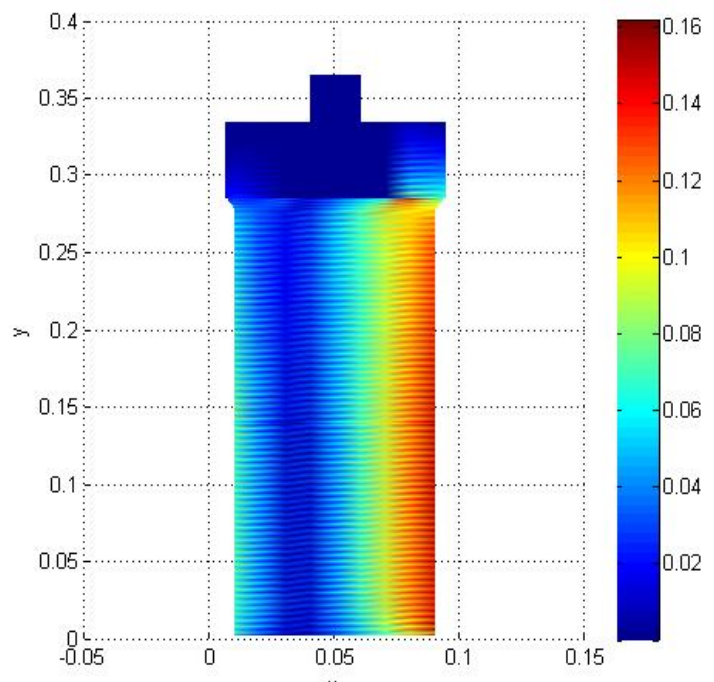

Figure 5. Distribution of strain rate on the femur

Table 2. Simulation of stress, strain, and strain rate of the 25 -year-old femur bone

\begin{tabular}{cccc}
\hline $\begin{array}{c}\text { Points of } \\
\text { Observation }\end{array}$ & Stress (N) & Strain & Strain rate \\
\hline$(1)$ & $1.9930 \mathrm{e}+004$ & 0.0011 & 0.0534 \\
$(2)$ & $-3.7380 \mathrm{e}+004$ & -0.0021 & 0.1075 \\
$(3)$ & $1.7673 \mathrm{e}+004$ & $9.3649 \mathrm{e}-004$ & 0.0471 \\
$(4)$ & $-3.6134 \mathrm{e}+004$ & -0.0021 & 0.1037 \\
$(5)$ & $2.2863 \mathrm{e}+003$ & $1.1111 \mathrm{e}-004$ & 0.0056 \\
$(6)$ & $-5.1517 \mathrm{e}+003$ & $-3.3844 \mathrm{e}-004$ & 0.0122 \\
Trabcular Bone (7) & 691.6219 & $-1.4813 \mathrm{e}-005$ & $7.4458 \mathrm{e}-004$ \\
Titanium (8) & $-2.8474 \mathrm{e}+003$ & $-2.0539 \mathrm{e}-004$ & 0.0103 \\
\hline
\end{tabular}

\section{The density of Bone Femur}

Table 2 showed a rough estimate of the density of bone by using equation thermodynamics V. Klika and F. Marsik. The simulation shows that the greater the strain rate received by cells, the more many cells osteoblast that can be activated. Cells osteoblast having sensitivity stimuli; one of them is stimuli mechanical. The consequent is on bone cells that are influence more force, the more many cells osteoblast of being turned. The more cells osteoblast that can be activated, the formation of bone will be bigger, so that bone density will increase. On a calculation, this research got that activity walk density bones have indigo higher than with the activity of standing. This because walk activity stimuli the force exerted on the greater than when standing.

\section{Limit of Bone Elasticity}

Calculations carried out using particle swarm (PSO) optimization. The results of equation (12) the show precision $\mathrm{C}$ different. A calculation Young's modulo in the break is influenced by the density of the bone cell in this phase. Meeting the density of bone cell, so Young's modulo who also generated bigger (table 3 ). 
Table 4. Comparison of simulation results with experimental cortical bone elasticity limits

\begin{tabular}{ccccc}
\hline Activity (Observation) & $\begin{array}{l}\text { Young's } \\
\text { Modulo }\end{array}$ & Ultimate Stress (N) & Experiment & Accuracy \\
\hline Stand (1) & 17.6185 & 112.9416 & - & - \\
Stand (2) & 17.9734 & 115.2166 & 122 & $94.11 \%$ \\
Walking Normally (1) & 18.0197 & 115.5134 & - & - \\
Walking Normally (2) & 18.3560 & 117.6692 & - & - \\
\hline
\end{tabular}

\section{Conclusion}

Based on the calculations, obtained elasticity limits around the bone connection with the activity of standing and walking. For the stem left on the activity of stand obtained Young's modulo 17.6185 GPa and the limits of elasticity $112.9416 \mathrm{MPa}$. As for the activity of walk to get Young's modulo 17.9734 $\mathrm{GPa}$ and the limits of elasticity 115.2166 MPa. For the stem right on the activity of stand obtained Young's modulo 18.0197 $\mathrm{GPa}$ and the limits of elasticity $115.5134 \mathrm{MPa}$. As for the activity of walk to get Young's modulo $18.3560 \mathrm{GPa}$ and the limits of elasticity $117.6692 \mathrm{MPa}$.

\section{Acknowledgment}

The author would like to thank the DIRJEN DIKTIS, UIN Maulana Malik Ibrahim Malang, and LP2M UIN Maulana Malik Ibrahim Malang.

\section{References}

1. Hill PA. Bone remodelling. Br J Orthod. 1998; 25:101-7.

2. Vaananen HK, Horton M. The osteoclast clear zone is a specialized cellextracellular matrix adhesion structure. J Cell Sci. 1995; 108:2729-2732.

3. Rouhi G. Biomechanics of Osteoporosis: The Importance of Bone Resorption and Remodeling Processes, Osteoporosis. Yannis Dionyssiotis (Ed.). 2012; ISBN: 978-953-51-0026-3.

4. Keaveny TM, Morgan EF, Oscar C. Bone mechanics. California(AS). McGraw-Hill; 2004.
5. Klika V, Marsik F.. Mathematical and numerical analysis of differential equations of bone remodelling. Czech technical university Faculty of nuclear science and physical Engineering Department of mathematics (CZ); 2006.

6. Klika V, Marsik F.. A thermodynamic model of bone remodelling: the influence of dynamic loading together with biochemical control. J Muscul Neur Inter. 2010; 10(3):220-230.

7. Idhammad A, Abdali A, Alaa N.. Computational simulation of the bone Remodeling using the finite element method: an elastic-damage theory for small displacements. Theor Biol Med Model. 2013;10:32.

8. Yakin, K.. Influence Of Mechanical Stimulation on Bone Tissue Elasticity With Fem. Journal Neutrino. 2018 Oct; 11(1): 11-20.

9. Martini FH, Nath JL, Bartholomew EF. Fundamentals of anatomy \& physiology 9th ed. San Francisco(AS). Publishing as Pearson Benjamin Cummings; 2009. 